\title{
Validation study of the Polish version of the Evidence-Based Practice Profile Questionnaire
}

\author{
Mariusz Panczyk ${ }^{1 *}$ D, Jarosława Belowska ${ }^{1}$, Aleksander Zarzeka ${ }^{1}$, Łukasz Samoliński ${ }^{1}$, \\ Halina Żmuda-Trzebiatowska ${ }^{2,3}$ and Joanna Gotlib ${ }^{1}$
}

\begin{abstract}
Background: Decisions about patient care in clinical practice should be made based on proven scientific evidence of efficacy and safety (i.e., evidence-based practice [EBP]). Currently, there are no available tools in Poland for assessing the knowledge and attitudes of specialists in health sciences towards EBP. Therefore, by validating the Polish version of the original English Evidence-Based Practice Profile Questionnaire (EBP $\left.{ }^{2} \mathrm{Q}\right)$, we may provide an appropriate instrument for assessing EBP.

Methods: The validation group consisted of 1,362 people, including nurses and midwives taking the specialization exam, second-degree students in nursing/midwifery, and staff of selected municipal and clinical hospitals in Warsaw, Pruszkow, and Chelm. The study was conducted from March to June 2014. The following psychometric properties of the $E B P^{2} Q$ were assessed: reliability (Cronbach's alpha coefficient, and test-retest), validity (exploratory factor analysis, Spearman's $r$ correlation coefficient, and assessment of inter-group differences), as well as unidimensionality of domains (principal component analysis).

Results: All domains of the $E B P^{2} \mathrm{Q}$ were characterized by high reliability (Cronbach's alpha ranging from 0.800 to 0.972 ). The Polish version showed a strong similarity of factor structure with the original English $\mathrm{EBP}^{2} \mathrm{Q}$, indicating that the condition for theoretical validity is fulfilled. Maintenance of the theoretical and discriminative validity and unidimensionality of five domains of the $E B P^{2} Q$ was confirmed.

Conclusions: The Polish version of the $\mathrm{EBP}^{2} \mathrm{Q}$ is comparable in terms of psychometry to the original English version. This questionnaire can be used to assess knowledge, attitudes, and skills concerning EBP among students and practicing professional nurses and midwives. The future validation of the $E B P^{2} \mathrm{Q}$ in other groups of specialists in health sciences may increase the scope of applicability of this tool.
\end{abstract}

Keywords: Psychometrics, Questionnaires, Reproducibility of results, Health knowledge attitudes practice, Evidence-based practice, Patient safety

\section{Background}

The paradigm of Evidence-Based Practice (EBP) is based on an assumption that clinical decisions in patient care are an outcome of patients' values, clinical circumstances and the best research evidence [1]. It is assumed that through such medical practice patients receive the best possible care that is not largely backed by tradition

\footnotetext{
*Correspondence: mariusz.panczyk@wum.edu.pl

'Division of Teaching and Outcomes of Education, Faculty of Health Science, Medical University of Warsaw, Żwirki i Wigury 61, 02-091 Warsaw, Poland Full list of author information is available at the end of the article
}

and convictions but stems from the most up-to-date research (the most valid and reliable scientific evidence) $[1,2]$. In addition, inclusion of patients' values in the decision-making process leads to increased acceptance of proposed treatment by the patient [3]. EBP principles, when followed by nurses, are believed to improve the quality of patient care, aid their professional development and help them accept responsibility for decisions made [3]. Further, application of EBP is likely to reduce costs of medical care by elimination of ineffective and risky medical procedures [4]. 
As a result of the above benefits arising from application of EBP principles, there is an increased focus on formation of EBP-related attitudes and skills in underand post-graduate education $[5,6]$. In order to make decisions based on the paradigm of the EBP, nurses need, on the one hand, to accept such a method of medical practice (a positive attitude), and on the other, they need to have the necessary skills and expertise required for a critical analysis of available scientific evidence [7]. Although the ability to use research results is an important part of the development of nurses and other related professions, there are numerous barriers to the implementation of EBP. One major obstacle is the insufficient competence of nursing staff in the practical aspects of EBP [8]. According to Solomons and Spross [9], additional training concerning searching, evaluation, and practical use of available scientific evidence is necessary at all levels of nurse education. Therefore, both professional studies and postgraduate education should involve training nurses in the methodology of research, as well as teaching them the skills necessary to use EBP at work $[10,11]$.

Implementation of appropriate educational solutions that are tailored to the individual needs of a particular group requires a preliminary assessment of competencies with the use of standardized questionnaires [12]. Most tools used to assess competence in EBP focus on individual elements of knowledge and skills that are necessary to implement care based on scientific evidence. In addition, questionnaires investigating the presence of potential barriers to implementation of the concept of EBP in the workplace have been developed, which evaluate the attitudes and behavior of individual members of the therapeutic team $[13,14]$. Despite this, an overview of the Polish scientific literature concerning EBP published in 2014 indicated that there are currently no available studies on the assessment of knowledge and attitudes of specialists in health sciences towards EBP [15]. In addition, there are unexplored areas, such as the level of competence in the EBP or the existing barriers in the implementation of the concept of EBP in Polish health care facilities. Indeed, no appropriate tools of proven psychometric properties have been developed in Poland that could be used to study key aspects of EBP functioning in individual groups of health sciences professionals.

Globally, a few types of questionnaires for assessing EBP are available, including: the Evidence-Based Practice Profile Questionnaire (EBP $\left.{ }^{2} \mathrm{Q}\right)[16]$, the Evidence-Based Practice Questionnaire for Nurses [17, 18], the Evidence-Based Nursing Attitude Questionnaire [19], the Evidence-Based Practice Attitude Scale [13], the Developing EvidenceBased Practice Questionnaire [20], and the Evidence Based Practice Evaluation Competence Questionnaire [21].
Although the range of available research tools is extensive, according to Shaneyfelt et al. [22], further development, adaptation, and evaluation of new questionnaires, adapted to local conditions and specifics of work in the given country are needed. Therefore, we adapted one of the more universal questionnaires, the $\mathrm{EBP}^{2} \mathrm{Q}$ [16]. The $\mathrm{EBP}^{2} \mathrm{Q}$ was developed at the University of South Australia by a team led by Maureen McEvoy, and was validated on 526 people (consisting of students, academic teachers, and practitioners) [16]. Apart from its good psychometric parameters, an additional advantage of the $\mathrm{EBP}^{2} \mathrm{Q}$ is its application to self-assessment of EBP competences by students, lecturers, and practitioners [16]. It can also assess different aspects of EBP by selecting individual parts (domains) of the questionnaire [16]. The purpose of this study was to validate the psychometric properties of a Polish version of the validated English $\mathrm{EBP}^{2} \mathrm{Q}$.

\section{Methods}

\section{Evidence-based practice profile questionnaire}

The original $\mathrm{EBP}^{2} \mathrm{Q}$ consists of 58 statements (all based on a five-point Likert scale), allowing the assessment of five domains (Relevance, Terminology, Confidence, Practice, and Sympathy) by the respondent. It is supplemented with additional questions necessary for the sociodemographic characteristics of respondents. In addition, the $\mathrm{EBP}^{2} \mathrm{Q}$ contains 16 statements, which have not been assigned to any of the five domains in the course of validation (Table 1).

The authors of the present study obtained the agreement of the authors of the original $\mathrm{EBP}^{2} \mathrm{Q}$ to use the tool in the studies conducted by the Medical University of Warsaw. The $E B P^{2} \mathrm{Q}$ in the form proposed by McEvoy et al. [16] was translated into Polish by two independent translators. Review and comparison of the two translations by the authors and a bilingual expert in nursing demonstrated their close similarity. The agreed version of the Polish translation was not subjected to reverse translation, and therefore, the final version of the questionnaire was not tested on bilingual people. The form of the agreed Polish version of the $\mathrm{EBP}^{2} \mathrm{Q}$ is included in Additional file 1.

\section{Data collection}

The study involved 1,362 people, including 1,195 (87.7\%) women, $42(3.1 \%)$ men, and 125 persons (9.2\%) who did not respond to the question regarding sex. The average age was 39.4 years (min. 20, max. 69, $\mathrm{SD}=10.32, \mathrm{CV}=$ $26.2 \%)$. The study group consisted of three subgroups: (1) nurses and midwives taking the state specialization exams organized by the Centre of Postgraduate Education for Nurses and Midwives in the spring session in 2014 $(N=596)$; (2) second-degree students of nursing and midwifery at the Medical University of Warsaw and 
Table 1 Structure of the $\mathrm{EBP}^{2} \mathrm{Q}$ with the separate domains and contained statements ${ }^{\mathrm{a}}$

\begin{tabular}{|c|c|c|}
\hline Domain & Item numbers & Description \\
\hline I. Relevance & 1-14 (14 items) & $\begin{array}{l}\text { Attitude towards expanding own competence in the Evidence-Based Practice, expressed on a scale } \\
\text { from } 1 \text { to } 5(1-\text { not at all true; } 5 \text { - very true) }\end{array}$ \\
\hline II. Sympathy & 15-21 (7 items) & $\begin{array}{l}\text { Attitude towards selected aspects of the Evidence-Based Practice in work, assessed by respondents } \\
\text { on a scale from } 1 \text { to } 5 \text { ( } 1 \text { - strongly disagree; } 5 \text { - strongly agree) }\end{array}$ \\
\hline III. Terminology & 22-38 (17 items) & $\begin{array}{l}\text { The level of knowledge about the terminology related to scientific research; given terms and issues } \\
\text { were rated on a scale from } 1 \text { to } 5 \text { ( } 1 \text { - never heard the term; } 5 \text { - understand and could explain to others) }\end{array}$ \\
\hline IV. Practice & 39-47 (9 items) & $\begin{array}{l}\text { Frequency of use of individual elements of Evidence-Based Practice in daily clinical work, assessed on } \\
\text { a scale from } 1 \text { to } 5 \text { ( } 1 \text { - never; } 5 \text { - daily) }\end{array}$ \\
\hline V. Confidence & 48-58 (11 items) & $\begin{array}{l}\text { Confidence in skills related to Evidence-Based Practice rated on a scale from } 1 \text { to } 5 \text { ( } 1 \text { - not at all confident; } \\
5 \text { - very confident) }\end{array}$ \\
\hline VI. Non-domain items & 59-74 (16 items) & $\begin{array}{l}\text { Other aspects of Evidence-Based Practice, expressed on a scale from } 1 \text { to } 5 \text { (1 - strongly disagree; } \\
5 \text { - strongly agree) }\end{array}$ \\
\hline VII. Demographics & -—— & Selected sociodemographic variables \\
\hline
\end{tabular}

all items based on a five-point Likert scale

The original English version of the EBP ${ }^{2} \mathrm{Q}$ is available at: http://www.biomedcentral.com/content/supplementary/1472-6920-11-100-s1.pdf

the Higher Vocational School in Kalisz $(N=462)$; and (3) nurses working in municipal and clinical hospitals in Warsaw, Pruszkow, and Chelm $(N=304)$. The study was conducted from March to June 2014. Participation in the study was voluntary and anonymous. Results were collected using an auditorium questionnaire, in which respondents were gathered in a single room at the hospital to complete self-administered questionnaires and the completed questionnaires were subsequently pooled.

\section{Methods of psychometric analysis}

$\mathrm{EBP}^{2} \mathrm{Q}$ validation was carried out in reliance on recommendations proposed by Downing [23] and Sullivan [24]. To evaluate the psychometric properties of the $\operatorname{EBP}^{2} \mathrm{Q}$, an analysis of reliability, validity, and unidimensionality of the five selected domains was performed. To assess the reliability of the $\mathrm{EBP}^{2} \mathrm{Q}$, analysis of the internal consistency of the given domain was applied, using the formula proposed by Cronbach [25]. According to Nunnally's criterion [26], a reliability threshold level with a Cronbach's alpha greater than 0.70 was considered acceptable. To assess the intrascale compatibility of particular statements, the correlation matrix was determined, and the value of $r>0.30$ was assumed the criterion for consistency [27].

The test-retest reliability was assessed in a group of 160 students who were retested using the $\mathrm{EBP}^{2} \mathrm{Q}$ following a 2-week interval. Absolute stability was measured by calculating the weighted kappa coefficient and the intra-class correlation coefficient (ICC) that determine the level of consistency of answers given between the first and the second measurement [24]. To establish a correct test-retest analysis, the assumption of equal means in two measurements was checked using the $t$ test [27]. The criteria for the assessment of the testretest reliability were analogous to those used for validation of the English version of the $\operatorname{EBP}^{2} \mathrm{Q}[16]$.
The validity of $\mathrm{EBP}^{2} \mathrm{Q}$ was assessed using three different analytical approaches. First, estimation of theoretical validity, also known as the internal validity, was performed by exploratory factor analysis. In particular, we explored whether the factor structure of the $\mathrm{EBP}^{2} \mathrm{Q}$ consists of five domains. Two different factor analysis criteria were used: (1) the Kaiser criterion, based on the number of factors with eigenvalues over one [28]; and (2) the Cattell's criterion, based on extracting the number of factors from the steep curve of the scree plot [29]. Both criteria were used as the Kaiser criterion can result in overestimating the number of factors (especially with the large number of items in the $\mathrm{EBP}^{2} \mathrm{Q}$ ), while the more conservative approach based on the scree plot gives more reliable results [30]. The fulfillment of assumptions for factor analysis was evaluated, the degree of homogeneity of variance was estimated, the determinant of the correlation matrix and the Kaiser-Meyer-Olkin (KMO) measure of sampling were determined, and the Bartlett's test of sphericity was performed. Second, estimation of theoretical validity, based on the determination of the degree of correlation between the selected domains of the questionnaire, was assessed. To verify the above assumption, the Spearman's rank correlation coefficient was calculated. Third, validity was estimated based on assessment of inter-group differences (discriminative validity). To do so, a comparative analysis of two groups of students was performed. One group took an e-learning EBP course $(N=119)$ while the control group did not participate in additional EBP classes $(N=207)$. A detailed training course had been previously published by Panczyk et al. [31]. The $t$ test was used to compare the groups and Cohen's $d$ was determined as a measurement of the effect of differences between means. The following criteria were assumed to assess the measured effect size: very strong $\geq 0.80$, strong $0.50-0.79$, average $0.49-0.20$, and poor $<0.2$ [32]. 
The analysis of unidimensionality of each $\mathrm{EBP}^{2} \mathrm{Q}$ domain was performed using principal component analysis. A domain was considered unidimensional if it met the Kaiser criterion [28] (i.e., designated eigenvalues exceeded the value of 1 only once), and if the degree of explanation of variability (i.e., using indicator variables via the first main component) exceeded $40 \%$.

All statistical calculations were performed using the statistical package $\mathrm{IBM}^{\circ} \mathrm{SPSS}^{\circ}$ Statistics, version 23. For all analyses, a P-level of $<0.05$ was considered statistically significant.

\section{Results}

\section{Analysis of reliability}

All five domains constituting the $\mathrm{EBP}^{2} \mathrm{Q}$ met Nunnally's criterion. Moreover, the mean correlations between individual statements for the corresponding domains were higher than the recommended value of 0.30 . The analysis of each domain, in terms of changes in the value of Cronbach's alpha coefficient after the removal of individual statements, showed that only the elimination of one domain item (No. 15) caused a slight increase in the value of the coefficient by 0.016 (see Additional file 2, "Reliability"). Details of the results of reliability analysis are presented in Table 2.

The assessment of test-retest reliability shows a good stability of scales in individual domains of the $\mathrm{EBP}^{2} \mathrm{Q}$. The assumption concerning the equality of the means for the repeated measurements was fulfilled, and the value ranges of weighted kappas and ICCs for the items were satisfactory (Table 3).

\section{Analysis of theoretical validity}

Before we estimated theoretical validity using factor analysis, we verified the fulfillment of the assumptions for this method. No statements showed a standard deviation of zero, and we confirmed the presence of homoscedasticity (Levene's test for equality of variances, $P>0.05$ ). In addition, the value of the determinant of the correlation matrix was close to zero $\left(1.4 \cdot 10^{-28}\right)$. Furthermore, the condition for sphericity was fulfilled, as it was found that a correlation coefficients matrix is not an identity matrix (Bartlett's test of sphericity, $P<0.0001$ ). The last condition of factor analysis was evaluated by the KMO test to

Table 2 Reliability of the Polish version of the $E^{2} P^{2} \mathrm{Q}:$ Cronbach's alpha coefficient

\begin{tabular}{llcc}
\hline Domain & Item numbers & Cronbach's alpha & Mean correlation \\
\hline I. Relevance & $1-14$ (14 items) & 0.937 & 0.698 \\
II. Sympathy & $15-21$ (7 items) & 0.798 & 0.532 \\
III. Terminology & 22-38 (17 items) & 0.971 & 0.801 \\
IV. Practice & 39-47 (9 items) & 0.923 & 0.725 \\
V. Confidence & $48-58$ (11 items) & 0.940 & 0.744 \\
\hline
\end{tabular}

assess the expected reduction rate. Adequacy of sampling (KMO index) was 0.949, which fulfills the assumptions for this parameter $(\mathrm{KMO}>0.5)$.

In the first attempt of exploratory factor analysis, 58 statements were distributed in accordance with the Kaiser criterion in eight domains, which was not consistent with the concept of the distribution of statements into five domains. However, interpretation of the scree plot (Cattell's criterion) indicated five domains (Fig. 1). In the next analysis, a 5-factor solution was imposed in accordance with the theoretical assumptions. It turned out that the variables located in five factors explained more than $63 \%$ of the total variance.

To facilitate the interpretation of the obtained nonorthogonal solution, direct oblimin rotation of raw factor loadings was performed. The resulting solution largely confirmed the proposed structure of the $\mathrm{EBP}^{2} \mathrm{Q}$. All domains proved to be theoretically valid. Only item No. 15 from domain II (Sympathy), did not load as expected with other statements of this domain. The result of the rotation indicates that this item belongs to domain I (Relevance) rather than domain II (Sympathy). Detailed summary of the results of the factor analysis for the direct oblimin rotation of loadings are included in Additional file 2, "Factor analysis".

Theoretical validity of the $\mathrm{EBP}^{2} \mathrm{Q}$ was also evaluated by calculating the Spearman's rank correlation coefficients based on the sum of the scores calculated for each of the domains. For domain II (Sympathy), a weak correlation with domain I (Relevance, $r_{\mathrm{s}}=0.13$ ) was found. No significant positive correlation with other domains of the $\mathrm{EBP}^{2} \mathrm{Q}$ was found (Table 4). Particularly good correlation coefficients were observed for domain IV with domain V and for domain III with domain IV. This indicates high criterion validity, which can be expressed as a positive correlation between the "Practice" and "Confidence" $\left(r_{\mathrm{s}}=0.60\right)$ and "Practice" and "Terminology" $\left(r_{\mathrm{s}}=0.51\right)$.

\section{Analysis of discriminative validity}

Within three domains (Relevance, Sympathy, and Terminology) the mean score of the students participating in the EBP training was significantly higher compared with that of the control group students. EBP training had a small to medium effect size on scores within these three domains (Cohen's $d$ 0.290.43). In the case of domain V (Confidence), however, the difference was on the border of statistical significance and the effect size was small $(P=0.054, d=$ $0.22)$. No significant effect was noted for the students' score in domain IV (Practice, $d=0.01$ ). The results of the validity assessment using the inter-group differences method are presented in Table 5. 
Table 3 Test-retest reliability of the questionnaire

\begin{tabular}{|c|c|c|c|c|c|c|}
\hline Domain & $\begin{array}{l}\text { Range of weighted kappas } \\
\text { for items in each domain }\end{array}$ & $\begin{array}{l}\text { Range of ICCs for } \\
\text { items in each domain }\end{array}$ & Domain ICCs & Mean difference & $\begin{array}{l}0.95 \mathrm{Cl} \text { for mean } \\
\text { difference }\end{array}$ & $P$-value \\
\hline I. Relevance & $0.35-0.74$ & $0.62-0.89$ & 0.94 & 0.42 & $-1.90-1.06$ & 0.577 \\
\hline II. Sympathy & $0.22-0.52$ & $0.22-0.67$ & 0.68 & 0.37 & $-1.24-0.50$ & 0.405 \\
\hline III. Terminology & $0.35-0.80$ & $0.59-0.91$ & 0.97 & 1.50 & $-3.28-0.28$ & 0.099 \\
\hline IV. Practice & $0.26-0.54$ & $0.43-0.70$ & 0.92 & 0.84 & $-2.04-0.36$ & 0.169 \\
\hline V. Confidence & $0.25-0.70$ & $0.52-0.85$ & 0.95 & 0.78 & $-1.77-0.22$ & 0.125 \\
\hline
\end{tabular}

${ }^{a}$ Kappa values $\geq 0.80$ were taken to represent excellent agreement, $0.60-0.79$ substantial agreement and 0.40-0.59 moderate agreement

${ }^{\mathrm{b}}$ For ICCs, values more than 0.75 indicated good reliability and less than 0.75 poor to moderate reliability

${ }^{\wedge} t$ test to compare mean differences in two measurements

\section{Assessment of unidimensionality of domains}

Based on a determined structure of the $\mathrm{EBP}^{2} \mathrm{Q}$, the unidimensionality of domains was evaluated. That is, we assessed whether each domain can be considered unidimensional. Using principal component analysis, we verified the eigenvalues and the share of variance explained by the first factor (Table 6). For domains III, IV, and V only one eigenvalue was greater than 1 , which, according to Kaiser criterion, demonstrated unidimensionality for each of them. For domains I and II, the second factor indeed exceeded the limit value of criterion, but the percentage of explained variance was above the expected threshold of $40 \%$.

\section{Discussion}

Although the concept of EBP has been known for decades, this concept is not widely known in the Polish nursing and obstetric environment [15]. With the development of nursing research, and the growing role of the results of these studies in the decision-making process, it has become necessary to implement new educational programs enhancing the qualifications of the personnel. However, if the actions taken in the field of education are to be effective, accurate assessment of the competencies and knowledge of nurses and midwives is necessary. For this purpose, the authors of this study attempted to develop and validate a linguistic adaptation (Polish) of the English $\mathrm{EBP}^{2} \mathrm{Q}$ (originally developed in Australia) to assess EBP in Poland [16]. This is the first standardized questionnaire in Poland, allowing us to comprehensively assess the knowledge, attitude, and behavior of students and health care professionals (including nurses and midwives) in terms of EBP.

As the Polish $E_{B P}{ }^{2} \mathrm{Q}$ is intended for use in a diverse group of nurses and midwives, as well as among students in these fields, a heterogeneous validation sample

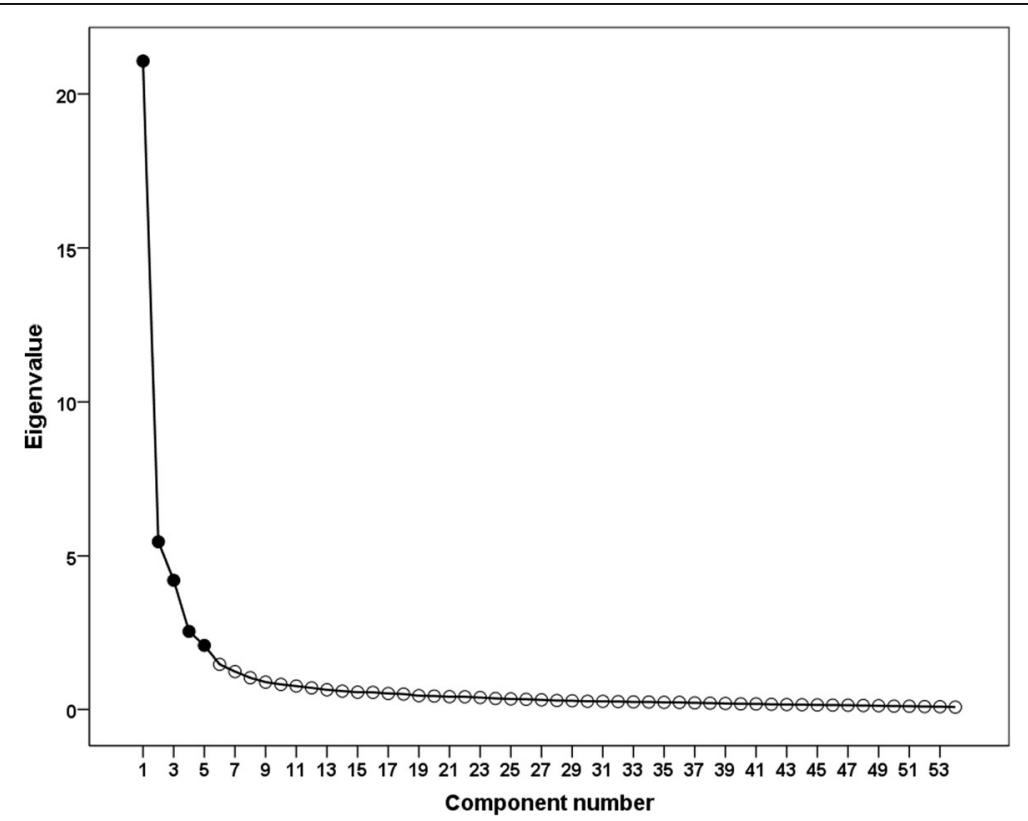

Fig. 1 Scree plot illustrating the components extracted from the data*. ${ }^{*}$ The number of components retained is five, as indicated by the change in shape of the plot after the fifth component. The labels indicate the percentage of variance explained by each factor 
Table 4 Correlation between the results for the individual domains: Spearman's rank correlation coefficients

\begin{tabular}{llllll}
\hline & \multicolumn{2}{l}{ Domain } & & & \\
\cline { 2 - 6 } & I & II & III & IV & V \\
\hline I. Relevance & -- & 0.13 & 0.49 & 0.45 & 0.49 \\
II. Sympathy & 0.13 & - & $-0.02^{*}$ & $-0.02^{*}$ & $0.05^{*}$ \\
III. Terminology & 0.49 & $-0.02^{*}$ & -- & 0.51 & 0.47 \\
IV. Practice & 0.45 & $-0.02^{*}$ & 0.51 & -- & 0.60 \\
V. Confidence & 0.49 & $0.05^{*}$ & 0.47 & 0.60 & - \\
\hline
\end{tabular}

*Correlation coefficients not statistically significant $(P>0.05)$

was chosen. We assume this provides adequate representation for evaluation of the psychometric parameters of the $\mathrm{EBP}^{2} \mathrm{Q}$ and its standardization across the various groups [33]. Our psychometric analysis confirmed the strong performance of the $\mathrm{EBP}^{2} \mathrm{Q}$. The reliability of the individual domains clearly exceeded the recommended value (Cronbach's alpha ranged from 0.800 to 0.972 ) $[25,26]$. Our results are similar to those obtained during the validation of the English $\mathrm{EBP}^{2} \mathrm{Q}$, in which Cronbach's alpha ranged from 0.760 to 0.940 [16]. The high reliability of the Polish $\mathrm{EBP}^{2} \mathrm{Q}$ contributes to a high degree of confidence in the measurement results obtained. This is linked to the low level of random errors, which do not exceed $10-20 \%$. Thus, random fluctuations in test results described in the classical theory of psychometric tests do not reduce the value of alpha in this case [34].

The results of the test-retest reliability analysis were also similar to those obtained during the validation of the original version of the $\mathrm{EBP}^{2} \mathrm{Q}$. Both the values of the ICCs (the Polish version: $0.68-0.97$ versus the English version: 0.77-0.94) and the differences between the means (the Polish version: $0.42-1.50$ versus the English version:-1.07-0.52) for the repeated measurements in individual domains of the $\mathrm{EBP}^{2} \mathrm{Q}$ were comparable to the results of the test-retest analysis published by McEvoy et al. [16]. The results for some statements making up the domains were slightly worse. Slightly lower values were observed for the lower limits of the range of weighted kappas compared with the values for

Table 5 Comparison of scores obtained in $E B P^{2} Q-12$ h e-learning course group vs. control group

\begin{tabular}{|c|c|c|c|c|}
\hline Domain & $\begin{array}{l}\text { No formal } \\
\text { training } \\
(N=207) \\
\text { mean (SD) }\end{array}$ & $\begin{array}{l}12 \mathrm{~h} \text { course } \\
(n=119) \\
\text { mean (SD) }\end{array}$ & $P$-value ${ }^{*}$ & $\begin{array}{l}\text { Effect size } \\
\text { Cohen's }\end{array}$ \\
\hline I. Relevance & $47.6(10.86)$ & $51.9(9.64)$ & 0.001 & 0.43 \\
\hline II. Sympathy & $20.7(3.77)$ & $22.0(4.29)$ & 0.005 & 0.32 \\
\hline III. Terminology & $38.7(17.28)$ & $43.4(14.71)$ & 0.010 & 0.29 \\
\hline IV. Practice & $20.2(9.08)$ & $20.3(7.38)$ & 0.925 & 0.01 \\
\hline V. Confidence & $37.0(8.40)$ & $38.8(7.63)$ & 0.054 & 0.22 \\
\hline
\end{tabular}

${ }^{*} t$ test to compare mean values
Table 6 The share of variance explained by first principal component analysis

\begin{tabular}{llc}
\hline Domain & Kaiser criterion ${ }^{\text {a }}$ & $\begin{array}{c}\text { The share of variance } \\
\text { explained by the first } \\
\text { principal component (\%) }\end{array}$ \\
\hline I. Relevance & $7.82 ; 1.91$ & 55.84 \\
II. Sympathy & $3.26 ; 1.13$ & 46.57 \\
III. Terminology & $11.63 ; 0.95$ & 68.41 \\
IV. Practice & $5.61 ; 0.72$ & 62.30 \\
V. Confidence & $6.95 ; 1.00$ & 63.18 \\
\hline
\end{tabular}

aeigenvalue of 1 and 2 factor, respectively

the original version of the questionnaire. However, due to the lack of detailed data from the test-retest analysis performed by McEvoy et al. [16], it is hard to assess whether the lower repeatability (weighted kappas $~ 0.40$ ) for some statements in both validation tests concerned the same items. To summarize the assessment of the test-retest reliability, the Polish version of the $\mathrm{EBP}^{2} \mathrm{Q}$ appears to have good parameters of absolute stability. This means that the results of the measurements in the individual domains of the $\mathrm{EBP}^{2} \mathrm{Q}$ show limited sensitivity to random changes [35].

Measurement results for the individual statements of the $\mathrm{EBP}^{2} \mathrm{Q}$ obtained during the psychometric evaluation indicate a fairly high degree of similarity in the scope of tested knowledge and attitudes among study participants. We found a small degree of variation in the validation group, which indicates high uniformity in measured traits (SD ranged from 0.81 to 1.38 ). These results are similar to those obtained by McEvoy et al. [16]. Similar results were also observed in relation to the mean score obtained by respondents for individual items of the questionnaire, and the absence of a "floor" and "ceiling" effect for the validation of the $\mathrm{EBP}^{2} \mathrm{Q}$ (extreme mean values for the English version were 1.71 and 4.09 versus 1.63 and 4.11 for the Polish version) (see Additional file 2 "floor and ceiling effect").

The assumptions for the validity assessment by factor analysis were the same as those applied in the validation of the English version of the questionnaire [16]. Both the results of Bartlett's test of sphericity ( $P$ $<0.0001)$ and the degree of expected reduction KMO index for the English version 0.92 versus 0.95 for the Polish version) were similar in both studies [16]. The domain structure of the Polish $E P^{2} \mathrm{Q}$ was found to be largely consistent with the validated English version. We only observed variability in domains I and II (Relevance and Sympathy). This is probably related to a different organization of the work environment and a slightly different scope of competencies of nurses in Poland and Australia. Generally, despite some differences, the results of analysis of the theoretical validity confirm a high degree of accordance 
between the planned Polish and validated English $E_{B P}{ }^{2} \mathrm{Q}$ in evaluating the knowledge and attitudes toward EBP.

The theoretical validity of the Polish $\mathrm{EBP}^{2} \mathrm{Q}$ also confirms the high quality of the measurement tool. Results of respondents, calculated as the sum of the scores obtained for the individual domains, were positively correlated with each other. The exception was domain II (Sympathy), which is associated with the design of the items constituting this domain. In particular, some of the items within domain II directly overlap with those found in domain I (Relevance) and were similar to those found in all other domains. It can therefore be assumed that the individual intercorrelations for the $\mathrm{EBP}^{2} \mathrm{Q}$ components confirm the fulfillment of the condition of theoretical validity. Therefore, some theoretical assumptions related to the construction of the $E B P^{2} \mathrm{Q}$ were confirmed by empirical observation, and the functioning of the Polish version is similar to the English $\mathrm{EBP}^{2} \mathrm{Q}$.

Regarding the assessment of discriminative validity, the validation tests slightly differed across studies in how they were performed. For the original version of the $E B P^{2} \mathrm{Q}$, McEvoy et al. [16] proposed comparing the scores obtained in three different groups of respondents. The control group was compared with two groups differing in duration and form of EBP training. In the presented Polish validation of the $\mathrm{EBP}^{2} \mathrm{Q}$, two groups were compared (the "no formal training" control group versus the e-learning group). For both tests, significant differences between the groups concerned the results of the measurements in domains I and III (Relevance and Terminology). As expected, both tests also showed no significant training effect on the results achieved in domain IV (Practice). The differences in the assessment of discriminative validity relating to domain $\mathrm{V}$ (Confidence) may be connected with different durations of EBP training in the validation tests. The method of conducting the EBP training is crucial to its effectiveness. Therefore, variations in training programs, including their duration (the Polish version: $12 \mathrm{~h}$ versus the English version: $\geq 20 \mathrm{~h}$ ) and form (the Polish version: e-learning versus the English version: EBP course as part of university education), may have significantly contributed to the observed differences.

The last element of psychometric assessment of the Polish $\mathrm{EBP}^{2} \mathrm{Q}$ was evaluation of unidimensionality of individual domains. As in the case of validity analysis, these results confirm the factor homogeneity of all the domains, with the exception of domains I and II. In particular, domain II was highly heterogeneous, which directly refers to the results of the evaluation of criterion validity parameter. As mentioned above, this may result from potential differences between Poland and Australia in terms of working conditions and professional competence of nurses or midwives.
The unambiguous results of the psychometric analysis of the Polish version of the $\mathrm{EBP}^{2} \mathrm{Q}$ allow us to assume that it can be used in practice as a tool for assessing the EBP-related competence of students and practitioners in the nursing or midwifery profession. The $\mathrm{EBP}^{2} \mathrm{Q}$ is a tool for measuring the knowledge, attitudes, and behavior of subjects in the field of EBP. The results of this assessment can be used to diagnose the barriers that hinder the implementation of EBP in the workplace. Moreover, the $\mathrm{EBP}^{2} \mathrm{Q}$ can be successfully used by the participants of courses to upgrade their skills in the field of EBP, both as an element of self-assessment, as well as a tool for measuring learning outcomes. The questionnaire can be also used when designing individual educational programs, indicating those areas of knowledge and skills to which particular attention should be paid in the learning process. Furthermore, the modular nature of the $E B P^{2} \mathrm{Q}$ is its undoubted advantage. In particular, the tool can be adjusted to the needs of an individual test by using only selected domains.

The $\mathrm{EBP}^{2} \mathrm{Q}$, as any tool, has some drawbacks. One of them is the impossibility to assess a subject's use of other types of evidence than scientific. Making clinical decisions on the basis of non-scientific evidence, personal experience, tradition or intuition is contrary to the EBP concept. The knowledge of subjects' attitudes to the use of non-scientific evidence in medical practice could boost the measurement validity. Another important drawback of the $\mathrm{EBP}^{2} \mathrm{Q}$ pertains to domain III (Terminology). This domain relates to the knowledge of certain terms connected with methodology of scientific research, but it includes only the knowledge around quantitative based terms and excludes terms connected with qualitative research.

One of the significant limitations of the present study is the lack of convergent validity analysis, it was not possible to determine this psychometric property due to the lack of another Polish tool available for evaluating similar domains to the $\mathrm{EBP}^{2} \mathrm{Q}$. In addition, further validation studies should assess the diagnostic ability of the Polish $\mathrm{EBP}^{2} \mathrm{Q}$, by performing research using the tool in educational situations (i.e., pre- and post-test).

\section{Conclusions}

The results of the psychometric analysis of the Polish $\mathrm{EBP}^{2} \mathrm{Q}$ confirm the high quality of this tool. In terms of reliability and validity, the Polish $\mathrm{EBP}^{2} \mathrm{Q}$ is comparable to the original English version. The questionnaire can be used both in educational activities (graduate and postgraduate studies), as well as an assessment tool among practicing professional nurses and midwives at various levels. 


\section{Additional files}

Additional file 1: Evidence-Based Practice Profile (EBP2) Questionnaire. Polska wersja językowa kwestionariusza. (PDF 830 kb)

Additional file 2: Data analysis. (XLSX $26 \mathrm{~kb}$ )

\section{Abbreviations}

EBP: Evidence-based practice; $E B P^{2} \mathrm{Q}$ : Evidence-based practice profile questionnaire; ICC: Intra-class correlation coefficient; KMO: Kaiser-Meyer-Olkin

\begin{abstract}
Acknowledgements
Language and editing support was provided by Proper Medical Writing Sp. z o.O. The authors want to thank Dr Barbara Kot-Doniec, the Director of the Center for Postgraduate Education of Nurses and Midwives in Warsaw, for realization of this study.

The authors want to thank all nurses that participated in this study.

Funding

There were no external funds in financing this study.

\section{Availability of data and materials}

The English version of datasets generated and/or analyzed during the current study available from the corresponding author on reasonable request. The original English version of the $E_{B P}^{2} Q$ is available at: http:// www.biomedcentral.com/content/supplementary/1472-6920-11-100-s1.pdf
\end{abstract}

\section{Authors' contributions}

$M P, J B$, and JG contributed to the original conception and design of the survey, and final revision of the manuscript for important intellectual content. JB and $\mathrm{AZ}$ designed and contributed to the construction of scale and variables. $Ł S, H Z Z T$ and JG contributed to the organization of the survey and data collection. MP made the psychometric analysis of the data. MP and JB contributed to interpretation of the data. MP wrote the first draft of the manuscript with revisions by JG. All authors read and approved the final manuscript.

\section{Competing interests}

The authors declare that they have no competing interests, no relationship or financial dependence to any organization or any person having a direct financial contribution in the subject of research or materials examined in this work (e.g., through employment, consultancies, stock ownership, honoraria).

\section{Consent for publication}

Not applicable.

\section{Ethics approval and consent to participate}

The authors sought advice from the Bioethics Committee of Medical University of Warsaw to conduct the presented study. As the "commission does not issue opinions on the survey, retrospective and other non-invasive scientific studies", approval was not required. Informed consent was obtained verbal from every participant from whom data was collected upon completion of the questionnaire.

\section{Author details}

'Division of Teaching and Outcomes of Education, Faculty of Health Science, Medical University of Warsaw, Żwirki i Wigury 61, 02-091 Warsaw, Poland. ${ }^{2}$ Division of Clinical Nursing, Faculty of Health Science, Medical University of Warsaw, Erazma Ciołka 27, 01-445 Warsaw, Poland. ${ }^{3}$ Centre of Postgraduate Education for Nurses and Midwives in Warsaw, Adolfa Pawińskiego 5A, 02-106 Warsaw, Poland.

Received: 16 August 2016 Accepted: 3 February 2017

Published online: 10 February 2017

\section{References}

1. Upton D, Upton P, Scurlock-Evans L. The reach, transferability, and impact of the Evidence-Based Practice Questionnaire: a methodological and narrative literature review. Worldviews Evid Based Nurs. 2014;11(1):46-54.

2. Brown CE, Wickline MA, Ecoff $L$, Glaser D. Nursing practice, knowledge, attitudes and perceived barriers to evidence-based practice at an academic medical center. J Adv Nurs. 2009;65(2):371-81.
3. Heydari A, Mazlom SR, Ranjbar H, Scurlock-Evans L. A study of Iranian nurses' and midwives' knowledge, attitudes, and implementation of evidence-based practice: the time for change has arrived. Worldviews Evid Based Nurs. 2014;11(5):325-31.

4. Melnyk BM, Fineout-Overholt E. Evidence-based practice in nursing \& healthcare: A guide to best practice. London: Lippincott Williams \& Wilkins; 2011.

5. McEvoy MP, Williams MT, Olds TS. Evidence based practice profiles: differences among allied health professions. BMC Med Educ. 2010;10:69.

6. Glasziou P, Burls A, Gilbert R. Evidence based medicine and the medical curriculum. BMJ. 2008;337:a1253.

7. Dawes M, Summerskill W, Glasziou P, Cartabellotta A, Martin J, Hopayian K, Porzsolt F, Burls A, Osborne J. Sicily statement on evidence-based practice. BMC Med Educ. 2005;5(1):1.

8. Majid S, Foo S, Luyt B, Zhang X, Theng YL, Chang YK, Mokhtar IA. Adopting evidence-based practice in clinical decision making: nurses' perceptions, knowledge, and barriers. J Med Libr Assoc. 2011;99(3):229-36.

9. Solomons NM, Spross JA. Evidence-based practice barriers and facilitators from a continuous quality improvement perspective: an integrative review. J Nurs Manag. 2011;19(1):109-20.

10. Blenkinsop C. Research: an essential skill of a graduate nurse? Nurse Educ Today. 2003:23(2):83-8

11. Callister LC, Matsumura G, Lookinland S, Mangum S, Loucks C. Inquiry in baccalaureate nursing education: fostering evidence-based practice. J Nurs Educ. 2005:44(2):59-64

12. Tilson JK, Kaplan SL, Harris JL, Hutchinson A, llic D, Niederman R, Potomkova J, Zwolsman SE. Sicily statement on classification and development of evidence-based practice learning assessment tools. BMC Med Educ. 2011;11:78.

13. Johnston JM, Leung GM, Fielding R, Tin KY, Ho LM. The development and validation of a knowledge, attitude and behaviour questionnaire to assess undergraduate evidence-based practice teaching and learning. Med Educ. 2003;37(11):992-1000.

14. Oude Rengerink K, Thangaratinam S, Barnfield G, Suter K, Horvath AR, Walczak J, Welminska A, Weinbrenner S, Meyerrose B, Arvanitis TN, et al. How can we teach EBM in clinical practice? An analysis of barriers to implementation of on-the-job EBM teaching and learning. Med Teach. 2011:33(3):e125-30.

15. Gotlib J, Belowska J, Panczyk M, Dykowska G, Wójcik G. Evidence-based Medicine and Evidence-based Nursing Practice - a review of the Polish scientific literature. Nursing Topics. 2014;22(2):223-7.

16. McEvoy MP, Williams MT, Olds TS. Development and psychometric testing of a trans-professional evidence-based practice profile questionnaire. Med Teach. 2010;32(9):e373-80.

17. Adams S, Barron S. Development and testing of an evidence-based practice questionnaire for school nurses. J Nurs Meas. 2010;18(1):3-25.

18. Upton D, Upton P. Development of an evidence-based practice questionnaire for nurses. J Adv Nurs. 2006;53(4):454-8.

19. Ruzafa-Martinez M, Lopez-lborra L, Madrigal-Torres M. Attitude towards Evidence-Based Nursing Questionnaire: development and psychometric testing in Spanish community nurses. J Eval Clin Pract. 2011;17(4):664-70.

20. Gerrish K, Ashworth P, Lacey A, Bailey J, Cooke J, Kendall S, McNeilly E. Factors influencing the development of evidence-based practice: a research tool. J Adv Nurs. 2007;57(3):328-38.

21. Ruzafa-Martinez M, Lopez-Iborra L, Moreno-Casbas T, Madrigal-Torres M. Development and validation of the competence in evidence based practice questionnaire (EBP-COQ) among nursing students. BMC Med Educ. 2013;13:19.

22. Shaneyfelt T, Baum KD, Bell D, Feldstein D, Houston TK, Kaatz S, Whelan C, Green M. Instruments for evaluating education in evidence-based practice: a systematic review. J Am Med Assoc. 2006;296(9):1116-27.

23. Downing SM. Validity: on meaningful interpretation of assessment data. Med Educ. 2003:37(9):830-7.

24. Sullivan GM. A primer on the validity of assessment instruments. J Grad Med Educ. 2011:3(2):119-20.

25. Feldt L. A test of the hypothesis that Cronbach's alpha or Kuder-Richardson coefficent twenty is the same for two tests. Psychometrika. 1969;34(3):363-73.

26. Nunnally JC, Bernstein IH. Psychometric theory (3rd ed.), vol. 226. New York: McGraw-Hill; 1967.

27. Jankowski K, Zajenkowski M. Methods for estimating the reliability of the measurement with the test. In: Fronczyk K, editor. Psychometrics - basics. Warszawa: Vizja Press \& IT; 2009. p. 84-110.

28. Kaiser HF. The varimax criterion for analytic rotation in factor analysis. Psychometrika. 1958;23(3):187-200. 
29. Cattell RB. The Scree Test For The Number Of Factors. Multivariate Behav Res. 1966;1 (2):245-76.

30. Osborne JW, Costello AB. Best practices in exploratory factor analysis: Four recommendations for getting the most from your analysis. Pan-Pacific Management Review. 2009;12:131-46.

31. Panczyk M, Belowska J, Zarzeka A, Gotlib J. Evaluation of learning outcomes at the Nursing Department in the field of Evidence-Based Medicine with the use of an e-learning Moodle ${ }^{T M}$ platform. Nursing Topics. 2015;23(3):306-13.

32. Cohen J. Statistical power analysis. Curr Dir Psychol Sci. 1992;1 (3):98-101.

33. Bedyńska S, Cypryańska M. Advanced ways to create indicators: the use of factor analysis and reliability analysis of the items. In: Bedyńska S, Brzezicka A, editors. Statistical signpost: Practical guide of data analysis in the social sciences. Warsaw: SWPS Academica Publishing House; 2007. p. 134-61.

34. Guilford JP. Psychometric methods. 2nd ed. New York: McGraw-Hill; 1954.

35. Weir JP. Quantifying test-retest reliability using the intraclass correlation coefficient and the SEM. J Strength Cond Res. 2005;19(1):231-40.

Submit your next manuscript to BioMed Central and we will help you at every step:

- We accept pre-submission inquiries

- Our selector tool helps you to find the most relevant journal

- We provide round the clock customer support

- Convenient online submission

- Thorough peer review

- Inclusion in PubMed and all major indexing services

- Maximum visibility for your research

Submit your manuscript at www.biomedcentral.com/submit
Biomed Central 